\title{
Fungal keratitis caused by Pseudallescheria boydii: clinical and mycological characteristics
}

\author{
Alireza Izadi ${ }^{1}$, Mohammad Soleimani ${ }^{2}$, Claudy Oliveira dos Santos ${ }^{3}$, Marlou C. Tehupeiory-Kooreman³, \\ Roshanak Daie Ghazvini ${ }^{1}$, Seyed Jamal Hashemi ${ }^{1}$, Mohssen Gramishoar ${ }^{1}$, Mehdi Aminizadeh², Zohre Abedinifar ${ }^{4}$, \\ Paul E. Verweij ${ }^{3}$ and Sadegh Khodavaisy ${ }^{1 *}$
}

\begin{abstract}
Background: Pseudallescheria keratitis is rare but important type of fungal keratitis because of the inherently resistance of the organism to many existing antifungal agents.

Methods: Slit-lamp and confocal microscopy were used for clinical examinations. Fungal isolates were identified based on morphological characteristics and DNA sequence of the internal transcribed spacer region (ITS). In vitro antifungal susceptibility testing for fungal isolates was performed according to the Clinical and Laboratory Standards Institute (CLSI, M38-A2).
\end{abstract}

Result: All patients had a history of ocular trauma. In clinical examination hypopion were seen in three patients. The main antifungal medications were topical voriconazole. After treatment the visual acuity of all patients improved in 2-3 weeks.

Conclusion: All four patients of Pseudallescheria keratitis had similar clinical features. Accurate and rapid identification of species should be helpful in treating $p$. boydii keratitis.

Keywords: Fungal keratitis, Pseudallescheria boydii, Antifungal

\section{Introduction}

Fungal keratitis is not life threatening but certainly cause ocular morbidity and sight threatening all over the world [1]. It has been caused by fungal species that capable to colonize and invade the ocular surface and corneal stroma [2]. The etiologic and epidemiologic pattern of fungal keratitis varies depending on patient status, geographic location, and climate [3]. Fungal keratitis can cause by at least 35 genera of moulds and yeasts [3, 4]. Pseudallescheria boydii (previously Petriellidium boydii, Allescheria boydii, Monosporium apiospermum) belongs to the group of septate filamentous fungi, which are the

\footnotetext{
* Correspondence: sadegh_7392008@yahoo.com

'Department of Medical Parasitology and Mycology, School of Public Health,

Tehran University of Medical Sciences, Tehran, Iran

Full list of author information is available at the end of the article
}

most common pathogenic fungi causing opportunistic human infections associated with trauma [5, 6]. This saprophytic fungus frequently isolated from soil, polluted water, sewage, decaying organic substances, manure, and potted plants throughout the world [7]. P. boydii implicated in a wide range of infections (mycetoma, pneumonia, osteomyelitis, arthritis, sinusitis, endocarditis, meningitis, and brain abscess) in both immunecompromised and immune-competent patients [7]. Several reports have documented eye infections such as keratitis, scleritis, sclerokeratitis, chorioretinitis, and endophthalmitis due to $P$. boydii following injury, herpetic keratitis and operation [8]. The first keratitis caused by Scedosporium species reported in 1955 [9]. The prognosis of fungal keratitis caused by $P$. boydii is poor [7]. Treatment of these pathologies is difficult because of the

\section{Springer Open}

(๑) The Author(s). 2021 Open Access This article is licensed under a Creative Commons Attribution 4.0 International License, which permits use, sharing, adaptation, distribution and reproduction in any medium or format, as long as you give appropriate credit to the original author(s) and the source, provide a link to the Creative Commons licence, and indicate if changes were made. The images or other third party material in this article are included in the article's Creative Commons licence, unless indicated otherwise in a credit line to the material. If material is not included in the article's Creative Commons licence and your intended use is not permitted by statutory regulation or exceeds the permitted use, you will need to obtain permission directly from the copyright holder. To view a copy of this licence, visit http://creativecommons.org/licenses/by/4.0/. 
inherently resistance of the organism to many existing antifungal agents $[8,9]$. We present the clinical characteristics, risk factors, treatment, and prognosis of four patients with $P$. boydii keratitis, and also present the antifungal sensitivities of the isolated strain.

\section{Methods}

\section{Subjects}

Slit-lamp and in vivo confocal microscopy (IVCM) (Heidelberg Engineering, Heidelberg, Germany) were used for clinical examinations. The clinical characteristics of four patients with Pseudallescheria keratitis were reviewed.

\section{Sample collection and processing}

Corneal scraping material was collected after anaesthetising the cornea with instillation of drops of $0.5 \%$ proparacaine and cleaning the cornea with sterile normal saline to remove all necrotic exudates. After $5 \mathrm{~min}$ with the help of blade no. 15 scraping was done under slit lamp illumination by the ophthalmologist. Corneal scrapings were sent to Medical Mycology laboratory, Tehran University of Medical Sciences, for mycology studies. Gram staining, 10\% Potassium Hydroxide $(\mathrm{KOH})$ mount, culture on sabouraud dextrose agar with chloramphenicol and slide culture was carried out to identify the isolate up to the genus level.

\section{Molecular identification}

One colony of each fungal species scraped and DNA was extracted using a DNA isolation kit (Gene All DNA extraction kit; Gene All, Germany) according to the manufacturer's instructions. To confirm the Pseudallescheria species identification, the Internal Transcribed Spacer (ITS) region was sequenced [10]. ITS 1 (5'-CGC TGC GTT CTT CAT CG-3') and ITS 2 (5'-TCG ATG AAG AAC GCA GCG-3') primers were used for amplification. Yielded sequence was subjected to Basic Local Alignment Search Tool (BLAST) program (http://www. blast.ncbi.nlm.nih.gov/Blast).

\section{Antifungal susceptibility}

In vitro antifungal susceptibility testing was performed according to the Clinical and Laboratory Standards
Institute (CLSI) M38-A2 for filamentous fungi [11]. Pseudallescheria species susceptibility of amphotricin B, 5 flucytosine, fluconazole, itraconazole, voriconazole, posaconazole, miconazole, caspofungin, chlorhexidin and natamycin was tested by determining minimum inhibitory concentration (MICs).

\section{Results}

\section{Clinical characteristics}

Data regarding age, sex, occupation, detailed clinical history, clinical presentation and symptoms are summarized in Table 1.

\section{Patient 1}

The patient was a 46-year-old woman who felt dust particles blow into her right eye during farm work. On clinical examination, her best-corrected visual acuity (BCVA) was counting fingers (CF) from $50 \mathrm{~cm}$. On slitlamp examination she had a grayish, superficial stromal infiltration with epithelial defect and indistinct margins. Hypopyon was detected in the anterior chamber (Fig. 1A). Examination of the cornea with the IVCM showed a mass of interlocking and branching white lines in the area of the infiltrate, this feature suggesting filamentous fungus keratitis (Fig. 2A). Based on clinical picture and the result of corneal scraping treatment were begun with oral itraconazole $(200 \mathrm{mg} /$ day $)$, topical $1 \%$ voriconazole hourly, topical $0.1 \%$ amphotricin B 2 time/ day and topical $0.5 \%$ levofloxacin 4 times/day. After medications the hypopyon resolved in a few days, the focal infiltrate resolved within 2 weeks and the BCVA in her right eye improved to 20/160 within 2 months.

\section{Patient 2}

A 69-year-old man attended our hospital with a sudden loss of visual acuity in left eye after trauma with plant material. On clinical examination, her BCVA was CF from $50 \mathrm{~cm}$. Slit-lamp examination showed corneal ulcer and associated hypopyon (Fig. 1B). Examination of the cornea with the IVCM showed branching white lines in the area of the infiltrate, this feature suggesting filamentous fungus keratitis (Fig. 2B). Based on clinical picture and the result of corneal scraping the patient was treated with application topical $1 \%$ voriconazole hourly and

Table 1 Clinical details of patients involved in this study

\begin{tabular}{|c|c|c|c|c|c|c|c|c|c|c|c|}
\hline Patient No. & Sex & Age & Job & Risk factor & Side & Size & VA1 & VA2 & Treatment & Hypopion & PKP \\
\hline 1 & Female & 46 & House wife & Injured by dust particle & OD & $3 \mathrm{~mm}$ & CF & $20 / 160$ & VRC, ITR, AMB & Yes & No \\
\hline 2 & Male & 69 & Farmer & Trauma with plant material & OS & $4 \mathrm{~mm}$ & HM & $20 / 200$ & VRC & Yes & No \\
\hline 3 & Male & 30 & Woodworker & Injured by wood particle & OS & $3.5 \mathrm{~mm}$ & CF & $20 / 19$ & VRC & Yes & No \\
\hline 4 & Male & 37 & Farmer & Trauma with plant material & OD & $4 \mathrm{~mm}$ & $20 / 60$ & $20 / 16$ & VRC & No & No \\
\hline
\end{tabular}

Abbreviations: OS Oculus sinister, $O D$ oculus dextrus, VA1 Visual acuity before treatment, VA2 Visual acuity after treatment, HM Hand motion, VRC Voriconazole; ITR: Itraconazole, AMB Amphotricin B, Eviscer Evisceration, PKP Penetrating Keratoplasty 

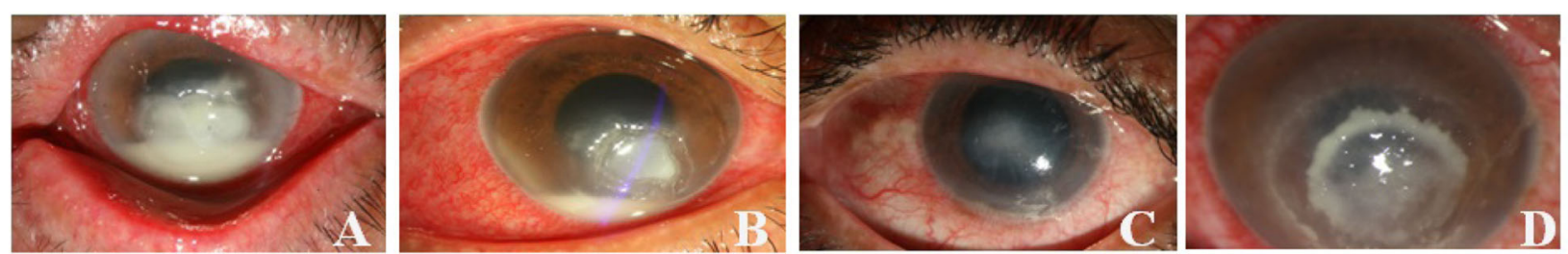

Fig. 1 Slit-lamp photographs of patients. Hypopyon can be seen in the anterior chamber of patient 1 (A) and patient 2 (B), A grayish, superficial stromal infiltrate with indistinct margins can be seen in patient 3 (C) patient 4 (D)

levofloxacin (4 times/day) for 4 weeks. Two weeks later hypopyon and focal infiltrate resolved. The BCVA in her left eye improved to 20/200 within 1 month.

\section{Patient 3}

The patient was a 30-year-old man whose left eye was injured by a wood particle during woodworking. He had history of pain, redness, sensation of foreign body, excessive tearing and diminution of vision in the left eye. On initial examination, her BCVA was CF from $50 \mathrm{~cm}$. On slit-lamp examination he had grayish white lesion involving the corneal endodermis, pyoderma in the endothelium, and peripheral corneal edema. Hypopyon was detected in the anterior chamber (Fig. 1C). Examination of the cornea with the IVCM showed branching white lines in the area of the infiltrate, this feature suggesting filamentous fungus keratitis (Fig. 2C). Based on clinical picture and the result of corneal scraping treatment were begun with topical $1 \%$ voriconazole hourly. After medications the hypopyon resolved in a few days, the focal infiltrate resolved within 2 weeks and the BCVA in her left eye improved to 20/19 within 2 months.

\section{Patient 4}

A 37-year-old man whose right eye was injured by a branch of a tree during farm work visited ophthalmology outpatient unit at our tertiary referral center. He had progressive pain, sensation of foreign body, excessive tearing and redness in the right eye. On initial examination, the BCVA of the right eye was found to be 20/60. Slit lamp examination of the affected eye revealed superficial corneal stromal infiltrate with gray-white in color and feathery edged margins. Satellite lesions and hypopyon were not seen. Based on clinical picture and the result of corneal scraping treatment were begun with topical $1 \%$ voriconazole hourly. After medications the focal infiltrate resolved within 10 days and the BCVA in her light eye improved to 20/16 within 1 month.

\section{Mycology characteristics}

Direct microscopic examination of scrapes using $\mathrm{KOH}$ and gram staining reveals septate hyphae. Gray-white fungal colonies grew on sabouraud dextrose agar after 3 days' incubation at $30^{\circ} \mathrm{C}$. Identification was subsequently made from microscopic examination of the colonies that showed ovoid conidia with hyphae which are features

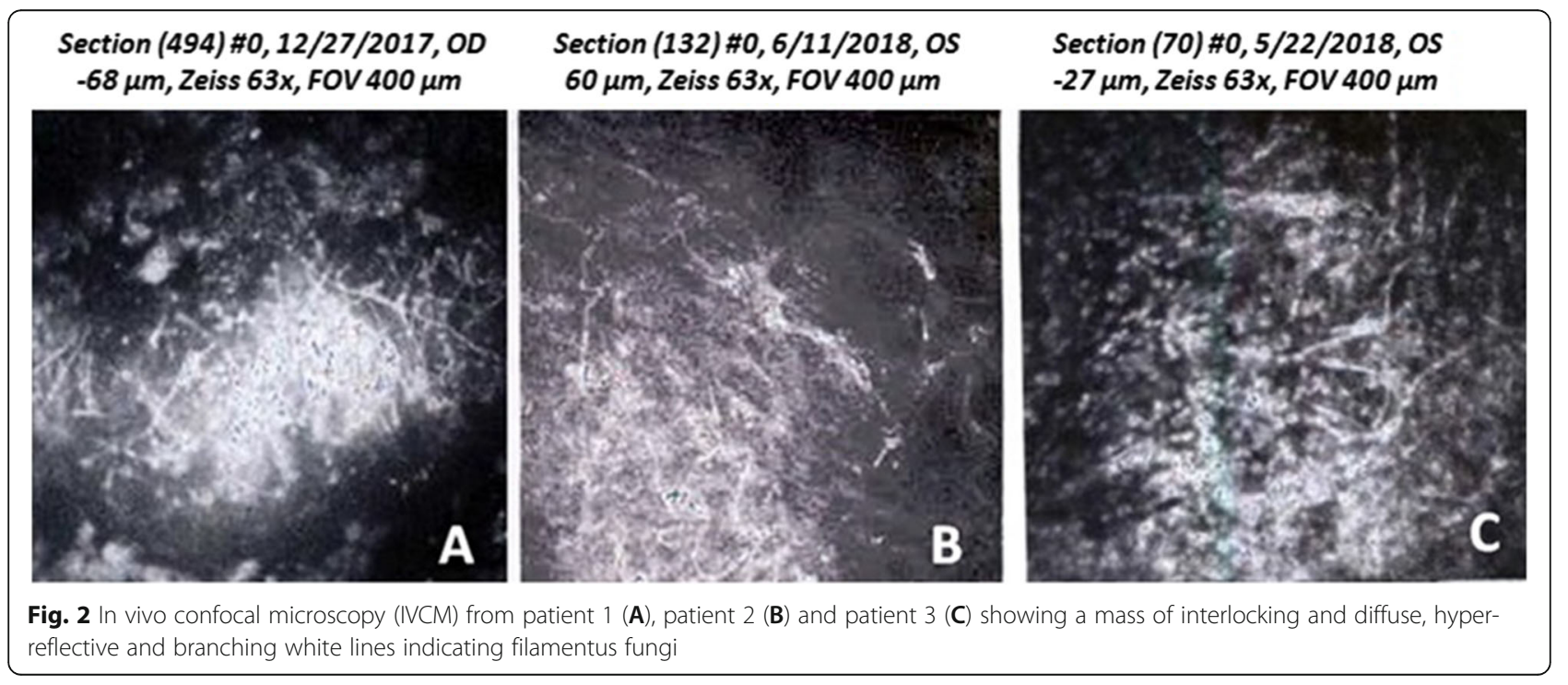


Table 2 MICs $(\mu \mathrm{g} / \mathrm{ml})$ of different antifungal drugs on the $P$. boydii isolates

\begin{tabular}{lllllllllll}
\hline & AMB & 5FC & FLU & ITR & VRC & PSO & MICO & CAS & Chlorhex & Nata \\
\hline Patient 1 & 4 & $\geq 64$ & 64 & 1 & 0.5 & 1 & 0.5 & 2 & 0.008 & 2 \\
Patient 2 & 4 & $\geq 64$ & $\geq 64$ & 1 & 0.5 & 0.5 & 0.5 & 0.5 & 0.008 \\
Patient 3 & 4 & $\geq 64$ & $\geq 64$ & 0.5 & 0.25 & 1 & 0.5 & 0.25 & 0.008 \\
Patient 4 & 4 & $\geq 64$ & 64 & 0.5 & 0.5 & 1 & 0.5 & 0.5 & 0.008 & 2 \\
\hline
\end{tabular}

Abbreviations: AMB Amphotricin B, FC 5 flucytosine, FLU Fluconazole, ITR Itraconazole, VRC Voriconazole, PSO Posaconazole, MICO Miconazole, CAS Caspofungin, Chlorhex Chlorhexidin, Nata Natamycin

characteristic of $P$. boydii. Using NCBI BLAST, the fungi isolates were identified as $P$. boydii with $100 \%$ identity in the GenBank database.

The Table 2 shows the MICs of various antifungal drugs against $P$. boydii isolates. The $P$. boydii isolates were sensitive to voriconazole, itraconazole, posaconazole, caspofungin and Chlor hexidin, while resistant to amphotericin B, 5-flucytosine, fluconazole and natamycin.

\section{Discussion}

$P$. boydii and its asexual form (S. apiospermum) belong to the group of septate filamentous fungi are uncommon cause of mycotic keratitis in humans. A review of the literature showed that $P$. boydii is the most common species of Scedosporium boydii complex (S. aurantiacum, P. minutispora, S. dehoogii, S. dehogii, and P. boydii) that reported as Pseudallescheria keratitis [12, 13]. To the best of our knowledge, fungal keratitis caused by P. boydii has only been reported in the literature as single cases [14-17]. For the first time, we describe the clinical and mycological features of four fungal keratitis caused by $P$. boydii over a one-year period in a training hospital. Rathi et al. reported that the principal risk factor for Pseudallescheria keratitis was ocular trauma [8]. The Pseudallescheria species are commonly found in soil, water, and sewage [9]. Thus, the principal risk factor for Pseudallescheria keratitis is ocular trauma and contamination by concomitant soil contamination [7, 9]. All of our patients (3 patient injured by plant material and 1 by dust particles) also gave a similar history of trauma.

Treatment of fungal keratitis remains a difficult problem for each ophthalmologist because there is no ideal antimycotic drug [12]. A delayed diagnosis and the use of conventional antifungals often lead to poor prognosis in Pseudallescheria keratitis [6]. Treatment is often based on clinical response [7]. Voriconazole was reported to be effective against $S$. apiospermum [7, 18]. However, it seems to be less effective against another Scedosporium species [19]. Viconazole treatment failure has sometimes resulted in the surgical procedure such as penetrating keratoplasty (PKP) [20]. Surgical procedure can result in complications such as pain, postoperative inflammation and graft rejection [21]. Hernandez et al. and Nulens et al. have reported voriconazole to be effective against fungal keratitis caused by $S$. apiospermum $[22,23]$. Ramakrishnan and colleagues reported in their series, natamycin and fluconazole combination therapy succeeded in seven of 10 cases of ocular infections caused by $S$. apiospermum [13]. Patients in our study were prescribed voriconzole alone without needing for surgical interventions and PKP. All patients showed complete healing of their ulcers with this monotherapy. In our antifungal susceptibility tests, all four strains displayed in vitro resistance to amphotericin B and fluconazole and susceptible to voriconazole and itraconazole. In vitro sensitivity tests for caspofungin displayed three isolates resistance and one isolate susceptible to this antifungal agent. There is few investigation of the antifungal susceptibility against $P$. boydi isolated from keratitis. Sicilia and colleagues have reported the isolated strain displayed in vitro resistance to all the antifungal agents (amphotericin B, fluconazole, itraconazole, ketoconazole and 5 -fluorocytosine) tested [7]. These results are some similar to our results. The chlorhexidine MICs of all isolates of $P$. boydi tested were $0.008 \mu \mathrm{g} / \mathrm{ml}$. Four patients with Fusarium keratitis were successfully treated with chlorhexidine $0.02 \%$ eye drops by Oliveira dos Santos et al. [24]. The efficacy of chlorhexidine for treating fungal keratitis has been confirmed by studies [24, 25]. There is a need for further research on the use of chlorhexidine in Pseudallescheria keratitis.

In conclusion, these patients bold the importance of determining causative organism of fungal keratitis and their antibiotic susceptibility. Culture findings are limited in identifying organisms. Sequencing of polymerase chain reaction-amplified DNA is good for accurate and rapid identification of species that can be helpful for optimize treatment.

\section{Abbreviations}

ITS: Internal transcribed spacer region; CLSI: Clinical and Laboratory Standards Institute; IVCM: In vivo confocal microscopy; KOH: Potassium Hydroxide; BLAST: Basic Local Alignment Search Tool; MICs: Minimum inhibitory concentration; BCVA: Best-corrected visual acuity; CF: Counting fingers

\section{Acknowledgments}

This study was part of a PhD. dissertation (grant No. 9611353001) supported by Tehran University of Medical Sciences. We owe a great debt of gratitude to Farabi Eye Hospital and their staff for their kind help. 


\section{Authors' contributions}

Al, MS and SK drafted the manuscript. Al, MS, CODS, MCTK, MG, MA, ZA and SK conducted the clinical examinations and Laboratory tests. Al, MS, RDG, $\mathrm{SJH}, \mathrm{PEV}$ and SK reviewed the manuscript and participated in the layout and design of the report. All authors read and approved the final manuscript.

\section{Funding}

This study has been funded and supported by Tehran University of Medical Sciences (TUMS); Grant no. 1400-1-99-53049.

\section{Availability of data and materials}

Not applicable.

\section{Declarations}

\section{Ethics approval and consent to participate}

All patients provided a signed written informed consent to undergo the treatment. This report was approved by ethics committee of Tehran University of Medical Sciences (IR.TUMS.MEDICINE.REC.1400.304).

\section{Consent for publication}

Not applicable.

\section{Competing interests}

The authors declare that they have no conflicts of interest.

\section{Author details}

'Department of Medical Parasitology and Mycology, School of Public Health, Tehran University of Medical Sciences, Tehran, Iran. ${ }^{2}$ Department of Ocular Trauma and Emergency, Farabi Eye Hospital, Tehran University of Medical Sciences, Tehran, Iran. ${ }^{3}$ Department of Medical Microbiology and Center of Expertise in Mycology Radboudumc/CWZ, Radboud University Medical Centre, Nijmegen, The Netherlands. ${ }^{4}$ Eye Research Center, Farabi Eye Hospital, Tehran University of Medical Sciences, Tehran, Iran.

Received: 22 June 2021 Accepted: 28 July 2021

Published online: 24 September 2021

\section{References}

1. Mahmoudi S, Masoomi A, Ahmadikia K, Tabatabaei SA, Soleimani M, Rezaie S, Ghahvechian $\mathrm{H}$ and Banafsheafshan A (2018) Fungal keratitis: An overview of clinical and laboratory aspects. Mycoses 61(12):916-930

2. Ghosh AK, Gupta A, Rudramurthy SM, Paul S, Hallur VK, Chakrabarti A (2016) Fungal keratitis in North India: spectrum of agents, risk factors and treatment. Mycopathologia 181(11-12):843-850. https://doi.org/10.1007/s11 046-016-0042-3

3. Ho JW, Fernandez MM, Rebong RA, Carlson AN, Kim T, Afshari NA (2016) Microbiological profiles of fungal keratitis: a 10-year study at a tertiary referral center. J Ophthalmic Inflam Infect 6(1):5. https://doi.org/10.1186/ s12348-016-0071-6

4. Kredics L, Narendran V, Shobana CS, Vágvölgyi C, Manikandan P, Group IHFK W (2015) Filamentous fungal infections of the cornea: a global overview of epidemiology and drug sensitivity. Mycoses 58(4):243-260

5. Fraco RM, Fraco GG (1992) Pseudallescheria boydii keratitis. Aust New Zeal J Ophthalmol 20(3):253-256. https://doi.org/10.1111/j.1442-9071.1992.tb00949. $x$

6. Bloom PA, Laidlaw D, Easty D, Warnock D (1992) Treatment failure in a case of fungal keratitis caused by Pseudallescheria boydii. Br J Ophthalmol 76(6): 367-368. https://doi.org/10.1136/bjo.76.6.367

7. Sicilia ML, Lacomba MS, Cuesta FS, Pedraza RS, Gomez TN, Roman MC (2003) Scedosporium apiospermum keratitis. Rev Iberoam Micol 20:68-70

8. Rathi HS, Venugopal A, Rengappa R, Ravindran M (2016) Scedosporium keratitis: an experience from a tertiary eye hospital in South India. Cornea 35(12):1575-1577. https://doi.org/10.1097//CO.0000000000000969

9. Tabatabaei SA, Tabatabaei M, Soleimani M, Tafti ZF (2018) Fungal keratitis caused by rare organisms. J Curr Ophthalmol 30(1):91-96. https://doi.org/1 0.1016/j.joco.2017.08.004

10. Klindworth A, Pruesse E, Schweer T, Peplies J, Quast C, Horn M et al (2013) Evaluation of general 165 ribosomal RNA gene PCR primers for classical and next-generation sequencing-based diversity studies. Nucleic Acids Res 41(1): e1-ee
11. Rex J, Alexander B, Andes D, Arthington-Skaggs B, Brown S, Chaturveil V (2008) Reference method for broth dilution antifungal susceptibility testing of filamentous fungi, vol 28. Approved Standard—second edition Clinical and Laboratory Standards Institute, Wayne

12. Ginderdeuren R, Foets B (2000) Fungal keratitis caused by Pseudallescheria boydii (Scedosporium apiospermum). Bull Soc Belge Ophtalmol 277:53-56

13. Ramakrishnan S, Mandlik K, Sathe TS, Gubert J, Krishnan T, Baskaran P (2018) Ocular infections caused by Scedosporium apiospermum: a case series. Indian J Ophthalmol 66(1):137-140. https://doi.org/10.4103/ijo.IJO_524_17

14. Wu Z, Ying H, Yiu S, Irvine J, Smith R (2002) Fungal keratitis caused by Scedosporium apiospermum: report of two cases and review of treatment. Cornea 21(5):519-523. https://doi.org/10.1097/00003226-200207000-00016

15. Ponchel C, Cassaing $S$, Linas M-D, Arné J-L, Fournié $P$ (2007) Kératite fongique à Scedosporium apiospermum. J Fr Ophtalmol 30(9):933-937. https://doi.org/10.1016/S0181-5512(07)74032-9

16. Atalay MA, Koc AN (2014) Fungal keratitis caused by Scedosporium apiospermum: first report from Turkey-comment. Mikrobiyoloji bulteni 48(2): 362-363. https://doi.org/10.5578/mb.7087

17. Saracli M, Erdem U, Gonlum A, Yildiran S (2003) Scedosporium apiospermum keratitis treated with itraconazole. Med Mycol 41(2):111-114. https://doi.org/10.1080/mmy.41.2.111.114

18. Rathbun RC, Hoffman HL (2002) Review of the safety and efficacy of voriconazole. Expert Opin Investig Drugs 11(3):409-429. https://doi.org/10.1 517/13543784.11.3.409

19. Espinel-Ingroff A, Boyle K, Sheehan DJ (2001) In vitro antifungal activities of voriconazole and reference agents as determined by NCCLS methods: review of the literature. Mycopathologia 150(3):101-115

20. Shah KB, Wu TG, Wilhelmus KR, Jones DB (2003) Activity of voriconazole against corneal isolates of Scedosporium apiospermum. Cornea 22(1):33-36. https://doi.org/10.1097/00003226-200301000-00008

21. Xie L, Zhai H, Shi W (2007) Penetrating keratoplasty for corneal perforations in fungal keratitis. Cornea 26(2):158-162. https://doi.org/10.1097/01.ico. 0000248381.24519.0d

22. Prats HC, Tello FL, José ABS, Otaolaurruchi JS, Baines JPO (2004) Voriconazole in fungal keratitis caused by Scedosporium apiospermum. Ann Pharmacother 38(3):414-417. https://doi.org/10.1345/aph.1D128

23. Nulens E, Eggink C, Rijs AJ, Wesseling P, Verweij PE (2003) Keratitis caused by Scedosporium apiospermum successfully treated with a cornea transplant and voriconazole. J Clin Microbiol 41(5):2261-2264. https://doi. org/10.1128/JCM.41.5.2261-2264.2003

24. Oliveira dos Santos C, Hanemaaijer NM, Ye J, van der Lee HA, Verweij PE, Eggink CA (2021) Chlorhexidine for the treatment of fusarium keratitis: a case series and Mini review. J Fungi 7(4):255. https://doi.org/10.3390/jof704 0255

25. Hoffman JJ, Yadav R, Sanyam SD, Chaudhary P, Roshan A, Singh SK et al (2020) Topical chlorhexidine $0.2 \%$ versus topical natamycin 5\% for fungal keratitis in Nepal: rationale and design of a randomised controlled noninferiority trial. BMJ Open 10(9):e038066

\section{Publisher's Note}

Springer Nature remains neutral with regard to jurisdictional claims in published maps and institutional affiliations.

\section{Submit your manuscript to a SpringerOpen ${ }^{\circ}$ journal and benefit from:}

- Convenient online submission

- Rigorous peer review

- Open access: articles freely available online

High visibility within the field

- Retaining the copyright to your article

Submit your next manuscript at $\boldsymbol{\nabla}$ springeropen.com 